Abstract THU0259 - Table 1. Characteristics of the UVEITIS in SpA subtypes TABLE. CHARACTERISTICS OF THE UVEITIS IN SPA SUBTYPES

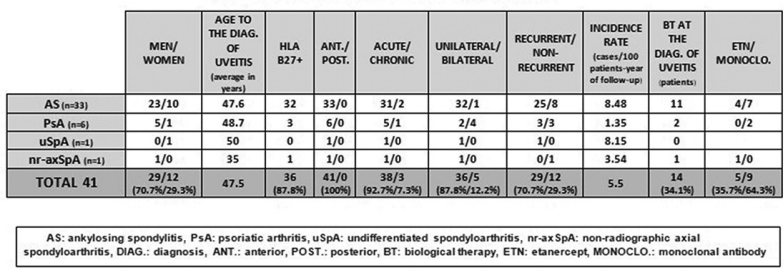

Conclusions: In our series, uveitis was observed in $16.7 \%$ of patients with SpA of which $80.5 \%$ were AS and $14.6 \%$ PsA. The most frequent uveitis was anterior, unilateral, acute and recurrent. In PsA, the association with HLA B27 was less frequent and was more bilateral. In most cases, the diagnosis was later than the SpA.

Disclosure of Interest: None declared

DOI: 10.1136/annrheumdis-2018-eular.4103

\section{THU0260 THE UVEITIS IMPACT STUDY: A SURVEY BY THE SPONDYLITIS ASSOCIATION OF AMERICA}

J.T. Rosenbaum ${ }^{1,2}$, R. Howard ${ }^{3}$, L.M. Savage ${ }^{4} .{ }^{1}$ Legacy Devers Eye Institute, Portland; ${ }^{2}$ Oregon Health and Science University, Portland, OR; ${ }^{3}$ Spondylitis Association of America, Van Nuys, CA; ${ }^{4}$ Spondylitis Association of America, Van Nuys, CA., USA

Background: Uveitis is the most common clinically apparent concomitant of ankylosing spondylitis. The implications of developing uveitis in association with AS could help to understand this association and assist both clinicians and patients.

Objectives: To compare survey responses from patients with AS and no history of uveitis to those with AS and a history of uveitis.

Methods: Patients associated with the Spondylitis Association of America (SAA) participated in a web based survey with telephone follow-up performed for a subset.

Results: 716 respondents replied that a physician had made a diagnosis of AS $30.4 \%$ of these patients had a history of uveitis. Patients with a history of uveitis tended to be older (median age 31 versus 23 years) and the median age for onset of uveitis was 18 years. Although patients with uveitis did not differ from patients without uveitis on many measures of function, medication, or disability, patients with uveitis were more likely to have heel pain $(56 \% v .45 \%, p<0.005)$, rib pain $(60 \%$ v. $50 \%, p=0.02)$, gut inflammation $(37 \%$ v $23 \%, p=0.0001)$, hypertension $(42 \% \vee 33 \%, p=0.02)$, fibromyalgia $(18 \% \vee 12 \%, p=0.03)$, psoriatic arthritis $(11 \% \vee 6 \%, p=0.02)$, or acid reflux ( $57 \% \vee 48 \%, p=0.03)$. Patients with uveitis were more like to be negatively impacted in the past week for the ability to concentrate $(18 \%$ v $12 \%$, very limited, $\mathrm{p}=0.03)$; the ability to read, listen, or watch TV $(15 \% \vee 9 \%$, very limited, $p=0.01)$; and the ability to enjoy family life or friends $(6 \% \vee 2 \%$, totally limited, $\mathrm{p}=0.005)$. Prednisone was more commonly used by those with uveitis ( $16 \% \vee 7 \%, p=0.0002)$; and while sulfasalazine was more commonly used previously $(41 \% \vee 24 \%, p<0.001)$, it was less commonly used currently $(7 \%$ v. $10 \%)$. Etanercept, which is less effective in preventing uveitis than monoclonal anti-TNF inhibitors, was used equally in the two groups (11\% v $12 \%)$. Conclusions: This survey suggests associations between uveitis and clinical manifestations such as heel pain, bowel disease, and skin disease. It is one of the first reports to suggest that uveitis affects quality of life such as the ability to enjoy family or friends. Although medications differentially affect uveitis, our study did not indicate an impact on therapy resulting from uveitis except for the current use of prednisone and a prior history of the use of sulfasalazine.

Acknowledgements: Funded by the Spondylitis Association of America

Disclosure of Interest: J. Rosenbaum Shareholder of: Novartis, Grant/research support from: Pfizer, Consultant for: Abbvie, UCB, Novartis, Regeneron, Gilead, R. Howard: None declared, L. Savage: None declared DOI: 10.1136/annrheumdis-2018-eular.4966

\section{THU0261 \\ CARDIOVASCULAR RISK STRATIFICATION IN ANKYLOSING SPONDYLITIS: LATERAL LUMBAR RADIOGRAPHY IS USEFUL TO DETECT HIGH- CARDIOVASCULAR RISK PATIENTS}

J.L. Martín-Varillas ${ }^{1}$, B. Atienza-Mateo ${ }^{1}$, N. Vegas-Revenga ${ }^{1}$, L. DominguezCasas $^{1}$, J. Rueda-Gotor ${ }^{1}$, F. Genre ${ }^{1}$, A. Corrales ${ }^{1}$, R. Blanco ${ }^{1}$, P. Fuentevilla ${ }^{1}$, V. Portilla ${ }^{1}$, R. Expósito' ${ }^{2}$, C. Mata ${ }^{2}$, T. Pina' ${ }^{1}$, C. González-Juanatey ${ }^{3}$, L. RodríguezRodríguez ${ }^{4}$, J.A. Parra ${ }^{5}$, M.A. González-Gay ${ }^{1}{ }^{1}{ }^{1}$ epidemiology, Genetics and Atherosclerosis Research Group on Systemic Inflammatory Diseases, Division of Rheumatology, Hospital Universitario Marqués de Valdecilla, IDIVAL, University of Cantabria, Santander, ${ }^{2}$ Division of Rheumatology, Hospital Comarcal de Laredo, Laredo; ${ }^{3}$ Division of Cardiology, Hospital Lucus Augusti, Lugo; ${ }^{4}$ Division of Rheumatology, Instituto de Investigación Sanitaria del Hospital Clínico San Carlos (IDISSC), Hospital Clínico San Carlos, Madrid; ${ }^{5}$ Radiology, Hospital Universitario Marqués de Valdecilla, Santander, Spain

Background: Ankylosing spondylitis (AS) is associated with increased rates of cardiovascular (CV) disease. CV events in these patients can be prevented by identifying patients at high risk who can benefit from appropriate primary prevention measures. The systematic coronary risk evaluation (SCORE) is the predictive model recommended in Europe, but it underestimates the CV risk in AS.

Objectives: To determine if a lateral lumbar radiography, which is available in most of AS patients, may help to identify AS patients at high risk of CV disease. Methods: 125 AS patients older than 35 years old without history of CV events, diabetes mellitus or chronic kidney disease were recruited. All patients underwent a carotid ultrasound (US) and lateral lumbar spine radiography and a multi-detector coronary tomography (MDCT) was also performed in a subgroup of 43 AS patients. Carotid plaques were defined according to the Mannheim consensus and the presence of AAC as calcific densities visible in an area parallel to the lumbar spine and anterior to the lower part of the spine. A Coronary Artery Calcification Score (CACS) superior to 100 were considered as a surrogate marker of coronary atherosclerosis. $\mathrm{CV}$ risk was calculated according to the total cholesterol systematic coronary risk evaluation (TC-SCORE).

Results: CV risk was categorised according to the TC-SCORE as low $(<1 \%$; $n=64)$, moderate $(\geq 1 \%$ and $<5 \% ; n=54)$ and high/very high risk $(\geq 5 \% ; n=7)$. Most patients with low TC-SCORE did not show CAA, which was only present in 3 patients $(4,68 \%)$. In contrast, $38,9 \%$ of patients included in the moderate-risk group had CAA. The lateral lumbar radiography showed a sensitivity to detect subclinical atherosclerosis lower than that observed by carotid US, which found plaques in $61 \%$ of patients with moderate TC-SCORE, but superior to the MDCT ( $61,9 \% \mathrm{Vs} 28,6 \%$ in the subgroup of 43 patients). $89 \%$ of patients with AAC also had carotid plaques $(r=0.49, p<0,0001)$. We set up a predictive model to disclose the largest number of $\mathrm{AS}$ with high/very high $\mathrm{CV}$ risk, defined by the presence of carotid plaques or a TC-SCORE $\geq 5 \%$ (table 1). A model including patients with a chart TC-SCORE $\geq 5 \%$ along with the presence of AAC showed a sensitivity of $50,9 \%$ (model 4 ). The combination of a TC-SCORE $\geq 5 \%$ and the performance of carotid US in patients with a moderate SCORE showed the highest sensitivity to detect patients at high/very high risk $(72,7 \%$, model 2$)$. Nevertheless, model 4 showed greater specificity than model $2(70 \%$ Vs $95.7 \%)$, leading to a higher global diagnostic accuracy (area under curve: 0,73 Vs 0,71 ).

Abstract THU0261 - Table 1

\begin{tabular}{|c|c|c|c|c|}
\hline & Sensitivity & Specificity & $\begin{array}{l}\text { Correctly } \\
\text { classified }\end{array}$ & $\operatorname{ROC}[95 \% \mathrm{CI}]$ \\
\hline $\begin{array}{l}\text { Model } 1 . \\
\text { TC. SCORE } \geq 5 \%\end{array}$ & $12.7 \%$ & $100 \%$ & $61.6 \%$ & $0.56[0.52-0.61]$ \\
\hline $\begin{array}{l}\text { Model } 2 \text {. } \\
\text { TC- SCORE } \geq 5 \% \text { OR } \\
\text { TC-SCORE } \geq 1 \%<5 \% \text { plus carotid Carotid } \\
\text { US (presence of plaques) }\end{array}$ & $72.7 \%$ & $70.0 \%$ & $71.2 \%$ & $0.71[0.63-0.79]$ \\
\hline $\begin{array}{l}\text { Model } 3 \text {. } \\
\text { TC-SCORE } \geq 5 \% \text { OR } \\
\text { TC-SCORE } \geq 1 \% \text { and }<5 \% \text { plus lateral lumbar } \\
\text { X-ray (presence of AAC) }\end{array}$ & $45.5 \%$ & $95.7 \%$ & $73.6 \%$ & $0.71[0.64-0.78]$ \\
\hline $\begin{array}{l}\text { Model } 4 \\
\text { TC-SCORE } \geq 5 \% \text { or } \\
\text { TC-SCORE }<5 \% \text { plus lateral lumbar X-ray } \\
\text { (presence of AAC) }\end{array}$ & $50.9 \%$ & $95.7 \%$ & $76.0 \%$ & $0.73[0.66-0.8]$ \\
\hline
\end{tabular}

Conclusions: Several AS patients at high CV risk who are underdiagnosed as having very high $\mathrm{CV}$ risk by the SCORE can be detected by a lateral lumbar radiography. 